\title{
miRNAs and their application in drug-induced liver
}

\section{injury}

The complex miRNA regulatory network plays an important role in diverse biological activities of physiopathological processes. In addition to the discovery of and research on the extracellular miRNAs detected in multiple biofluids, the properties of tissue specificity and high stability underlie the great potential of these small miRNAs to serve as translational biomarkers for various diseases in the clinical setting, including in drug-induced liver injury. In this review, we describe the major technologies currently used and challenges in miRNA measurement and provide information on major bioinformatics resources available for current miRNA research. We also discuss novel findings in liver disease and highlight the potential of miRNAs for clinical and basic research as translational biomarkers for drug-induced liver injury.

\section{KEYWORDS: drug-induced liver injury microRNA translational biomarkers}

Drug-induced liver injury (DILI) is a leading cause of acute liver failure in the USA and one of the key safety issues in drug development and postmarketing surveillance [1-3]. To date, the most commonly used biomarkers for DILI, such as ALT and AST, are not specific. There is a clear need for alternative biomarkers of DILI that possess more sensitivity and specificity for detection of DILI than the conventional markers. Identifying more reliable and specific biomarkers for DILI by using emerging and high-throughput technologies has been an active field of research. However, to date, the challenge remains not only the earlier identification of DILI and distinguishing severe DILI that can lead to life-threatening conditions, but also the accountability in translation to clinical use of such approaches. It is also important to discover translational biomarkers linked to mechanistic information about the injury using state-of-art technologies for drug development and clinical use.

Post-transcriptional regulation of genes is now recognized as an important factor of disease pathogenesis [4]. The discovery of miRNAs as a new class of regulators of gene expression has triggered an explosion of research activities and emerged as an important set of markers for drug discovery and development [5,6]. As key regulators in gene expression networks, miRNAs can influence different biological processes [7]. They have extremely interesting potential for diseasestate biomarkers, and as well as in the toxicological context for tissue injury-specific biomarkers $[8,9]$. Unlike mRNA, miRNA has been shown to be remarkably stable in a variety of tissues and body fluids [10,11]. This property greatly facilitates the use of miRNAs as translational clinical biomarkers of disease and injury $[8,12,13]$. The development of screening and diagnostic tests for various diseases based on analysis of miRNA in body fluids - mainly in plasma or serum, but also in urine, saliva, cerebrospinal fluid and milk - is a very active area of research [14]. Individual miRNAs and miRNA profiles have been applied as biomarkers for early diagnosis and prognosis in different clinical manifestations of liver diseases, including DILI [15-17].

In this review, we describe the strengths and pitfalls of the emerging methodologies and technologies utilized for miRNA analysis. We also provide a summary of information on the major bioinformatics resources available for the current miRNA research. Finally, we discuss miRNA as biomarkers in liver diseases and highlight the current understanding of the roles of different miRNAs and the application of miRNAs as potential translational biomarkers for DILI.

\section{miRNA: biogenesis \& function}

miRNA are short (20-25 nucleotide) regulatory factors of gene expression [18] Advanced studies have revealed unexpected diversity in their biogenesis pathways and regulatory mechanisms [7,19]. Figure 1 is a schematic diagram showing the process of miRNA biogenesis. Biogenesis of miRNAs is a multistep process [20] including the production of primary miRNA transcripts (pri-miRNA) transcribed by RNA polymerase II or III and cleavage of the primary miRNA to yield approximately 70-100 nt hairpin precursor miRNAs (pre-miRNA) by the microprocessor

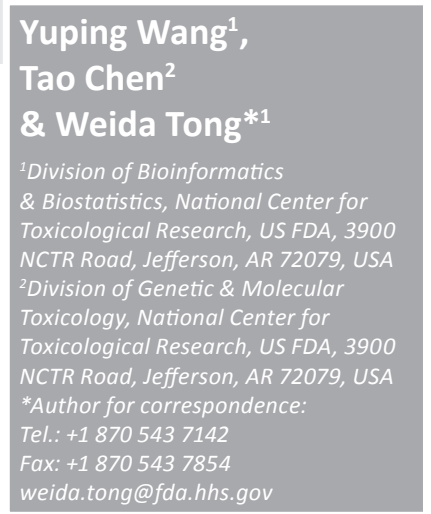

Future
Medicine $\mathrm{fS}$ 


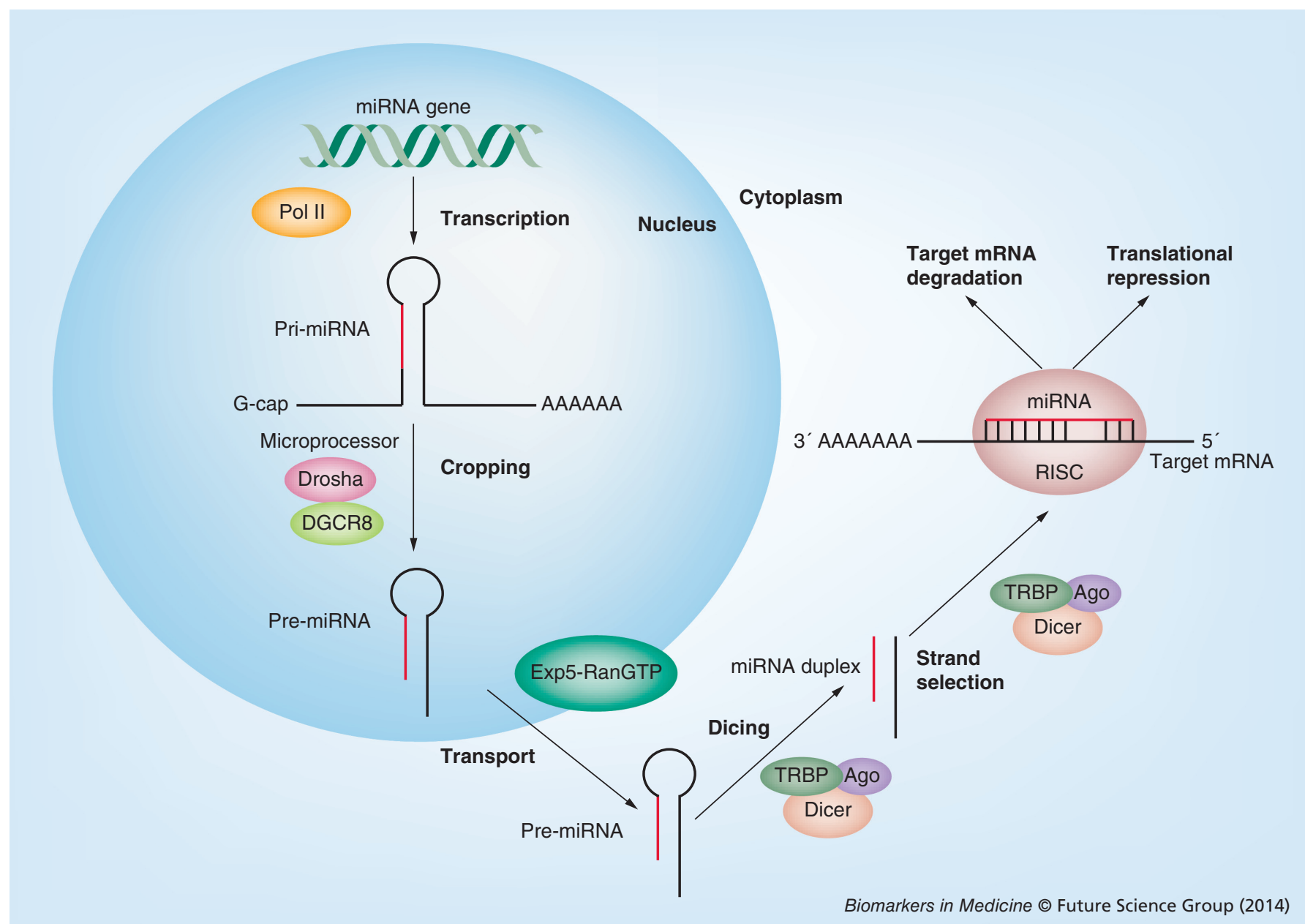

Figure 1. General mode of miRNA biogenesis.

RISC: RNA-induced silencing complex.

complex DGCR8 in the nucleus. The premiRNA is then exported from the nucleus by Exportin-5-Ran-GTP to the cytoplasm, then further processed by the RNase Dicer in complex to form a duplex of mature miRNA (miRNA/miRNA* duplex). Ultimately, the RNA duplex is unwound and the single-strand mature miRNA is incorporated into the protein complex to function as a guide, directing the silencing of target mRNA.

The control of miRNAs of gene expression is generally through inhibitory effects on protein translation by binding to the mRNA of their target genes [21]. Over the past decade, miRNAs have been shown to play important roles in biological systems and processes, such as organ development, cell proliferation and tumorigenesis [22-25]. Particularly, miRNA-based regulation has directly associated with disease etiology and treatment [26-30]. The discovery that a large amount of tissue-specific miRNAs exist in serum, plasma and other biofluids has led to intensive investigations on circulating miRNAs and potential as biomarkers for diseases and drug development $[17,31,32]$. However, challenges still remain.

\section{Technical challenges of miRNA isolation \& detection \\ Current approaches \& issues for miRNA samples preparation}

miRNAs have been isolated from many body fluids, and most tissues [33-37]. Ideally, this isolation should be specific for miRNA. A more important approach is to elucidate tissue-specific miRNA functions by combining matching miRNA and protein expression data with miRNA target prediction and mechanistic models of gene network regulation. However, there are numerous technical variables that could affect miRNA analysis leading to erroneous results. This is a particular concern and critical when miRNAs are utilized as translational biomarkers in clinical application.

There are many products for miRNA extraction supplied commercially. Generally, these technologies designed for miRNA quantification 
and integrity assessment use an Agilent Bioanalyzer [38-40]. Different extraction methods may influence the gene expression analysis of these small RNAs [40]. Major methodologies for miRNA extraction and quality considerations from various biological samples are summarized in TABLe 1. Generally, cultured cells and fresh frozen tissues produce high-quality miRNA that is suitable for miRNA expression profiling. However, most of biofluids are difficult specimens to work with due to the very low level of miRNA and other preanalytical variables. For example, miRNA detected in biofluids may have cellular pallets and an extracellular origin. However, only the latter is the most interesting in terms of biomarker discovery. Avoiding cellular contamination and hemolysis are therefore very important challenges [41,42]. Furthermore, biofluids, such as serum/plasma, contain inhibitors of the reserve transcriptase and polymerase enzymes used in the quantitative PCR (qPCR) reaction. In addition, miRNAs are secreted into blood circulation with extracellular vesicles, known as exosomes and microvesicles [43,44], or associated with Argonaute 2-containing protein complexes $[45,46]$. These extracellular vesicles play important roles in intercellular communication by serving as vehicles for transfer of cytosolic proteins, lipids and RNA between cell membranes. Thus, sample processing procedures that alter the vesicle contents may consequently influence miRNA profiles. Considering the relatively high cost and time consumption for miRNA expression profiling, more efforts should be put into the preanalytical variables to develop a standardized protocol for sample preparation and specific parameters for miRNA assessment.

\section{- Advantages \& disadvantages of current technologies for miRNA expression profiling}

miRNA analysis has provided great promise in basic and applied scientific research. Most well-established molecular and biological technologies have been successfully transferred into miRNA research. A number of miRNA expression profiling methodologies have been developed, such as microarray and real-time reverse-transcription PCR (qRT-PCR) [47-49]. There is, however, a lack of consensus regarding optimal methodologies for miRNA quantification. The diverse methods for data analysis make the comparison of different platforms and integration of cross-platform miRNA profiling data even more challenging. A summary of the major platforms currently used in miRNA research is listed at Table 2. Each methodology has benefits and limitations. Over the last decade, microarray profiling and qPCR have provided great contributions to the evaluation of miRNA expression in the research community. However, limitations for these technologies still remain. As we know, miRNAs are significantly complicated compared with other nucleic acids owing to their biological properties and expression patterns. For instance, for the PCR technology, due to the very short length of mature miRNAs and the fact that many miRNAs differ by only one or a few bases, in general, miRNAs are not amenable for specific primer annealing under standard PCR conditions. Some unique signatures of miRNAs, such as their small total number (compare to other mRNAs), short length (20-25 nucleotides) and the low expression level for majority of miRNAs, have created technical obstacles for direct application in various array platforms. Highthroughput, high-resolution next-generation sequencing (NGS) for miRNA profiling may offer promise to accurately identify the presence of known miRNAs and discover novel miRNAs in the near future.

Since its first use 8 years ago, NGS has been demonstrated as a potential platform for small RNA analysis and developed rapidly on its way to replace other technologies for DNA and

Table 1. Major biospecimens for miRNA extraction.

\begin{tabular}{|llr|}
\hline Sample type & General considerations on quality & Ref. \\
\hline Cell lines & Usually high-quality miRNA & {$[99]$} \\
\hline Cerebral spinal fluid & Can evaluate cell pellet and supernatant & {$[96]$} \\
\hline $\begin{array}{l}\text { Formalin-fixed } \\
\text { paraffin-embedded tissue }\end{array}$ & More reliable than mRNA as an analyte in formalin-fixed & {$[100]$} \\
\hline Fresh frozen tissue & Cell type heterogeneity & {$[101]$} \\
Plasma or serum & $\begin{array}{l}\text { RNases, low yield, generally, cannot measure quantity of } \\
\text { extracted RNA }\end{array}$ & {$[102]$} \\
\hline Urine & Can evaluate cell pellet versus supernatant & {$[103]$} \\
\hline
\end{tabular}


Table 2. Platforms comparison for miRNA profiling.

\begin{tabular}{|c|c|c|c|}
\hline Items & Reverse-transcriptase qPCR & Microarray & RNA-seq \\
\hline Principle & PCR application & Hybridization & Sequencing \\
\hline Throughput & Medium to high & High & Ultrahigh \\
\hline Costs & Economic & Economic & Comparatively high \\
\hline $\begin{array}{l}\text { Preferential field of } \\
\text { application }\end{array}$ & $\begin{array}{l}\text { Relative and absolute quantification; } \\
\text { validation of other miRNA profiling } \\
\text { approaches }\end{array}$ & $\begin{array}{l}\text { Relative and absolute quantification of } \\
\text { miRNA regulation; miRNA biomarker } \\
\text { identification; routine application and } \\
\text { higher throughput with respect to } \\
\text { sample number compared with small } \\
\text { RNA sequencing }\end{array}$ & $\begin{array}{l}\text { De novo identification of small RNAs; } \\
\text { simultaneous relative quantification } \\
\text { of different small RNA species; } \\
\text { holistic picture of the small RNA } \\
\text { transcriptome }\end{array}$ \\
\hline Disadvantages & $\begin{array}{l}\text { Only medium throughput with } \\
\text { respect to the number of samples } \\
\text { processed per day; cannot identify } \\
\text { novel miRNAs }\end{array}$ & $\begin{array}{l}\text { Lower specificity than reverse- } \\
\text { transcriptase qPCR or RNA } \\
\text { sequencing. Cannot identify novel } \\
\text { miRNAs; difficult to use for absolute } \\
\text { quantification }\end{array}$ & $\begin{array}{l}\text { Substantial computational support } \\
\text { needed for data analysis. Cannot be } \\
\text { used for absolute quantification }\end{array}$ \\
\hline
\end{tabular}

RNA analysis [50,51]. The increased resolution of NGS data provides a better understanding of the molecular processes that control the morphology and behavior of cells. NGS can provide unprecedented progress for insights into genomes [52]. Extensive studies using deep sequencing platforms have revealed unexpected complexity in relation to miRNAs, including 5'- and 3'-end-length heterogeneity and RNA editing. Moreover, the NGS systems directly count the number of transcripts found as a measure of expression abundance [53,54]. In particular, the technology is not limited by a predefined number of features, such as probe design, probe cross-hybridization or array background issues. Therefore, NGS is well suited to the discovery of novel miRNA species and small RNA transcription profiling, with an unprecedented sensitivity and resolution $[55,56]$.

Although specific products and techniques vary, each platform is relatively stable in terms of its own miRNA profiling intrareproducibility; however, the poor interplatform consistency remains a great challenge for data integration and comparing across platforms. The best choice depends on the applications and a balance of cost, precision, accuracy and sample quantity. If the purpose is to screen a bunch of samples to find a few altered miRNAs and you can tolerate certain false-negative results, the microarray may be the best platform. If the purpose is to detect individual miRNAs while the sample amount is a limiting step, qRT-PCR is the best choice owing to its sensitivity. If you are trying to find different isoforms or silent miRNAs and to discover novel miRNAs, then the NGS is the best approach.

\section{Bioinformatics resources for miRNA target prediction \& interpretation of discovered miRNAs}

Controversially, despite advent in the development of technologies in detecting miRNA and more knowledge of the basic mechanism of action of miRNAs gaining, the main challenges for miRNA research still remain [57], for instance, the identification of miRNA targets to understand how they fine tune so many biological processes in both healthy and diseased tissue [58,59]. Toward this end, bioinformatics algorithms and computational approaches are playing a significant role in miRNA data analysis, including target identification [60]. The first computational miRNA target prediction approaches were developed independently by several groups during 2003 and 


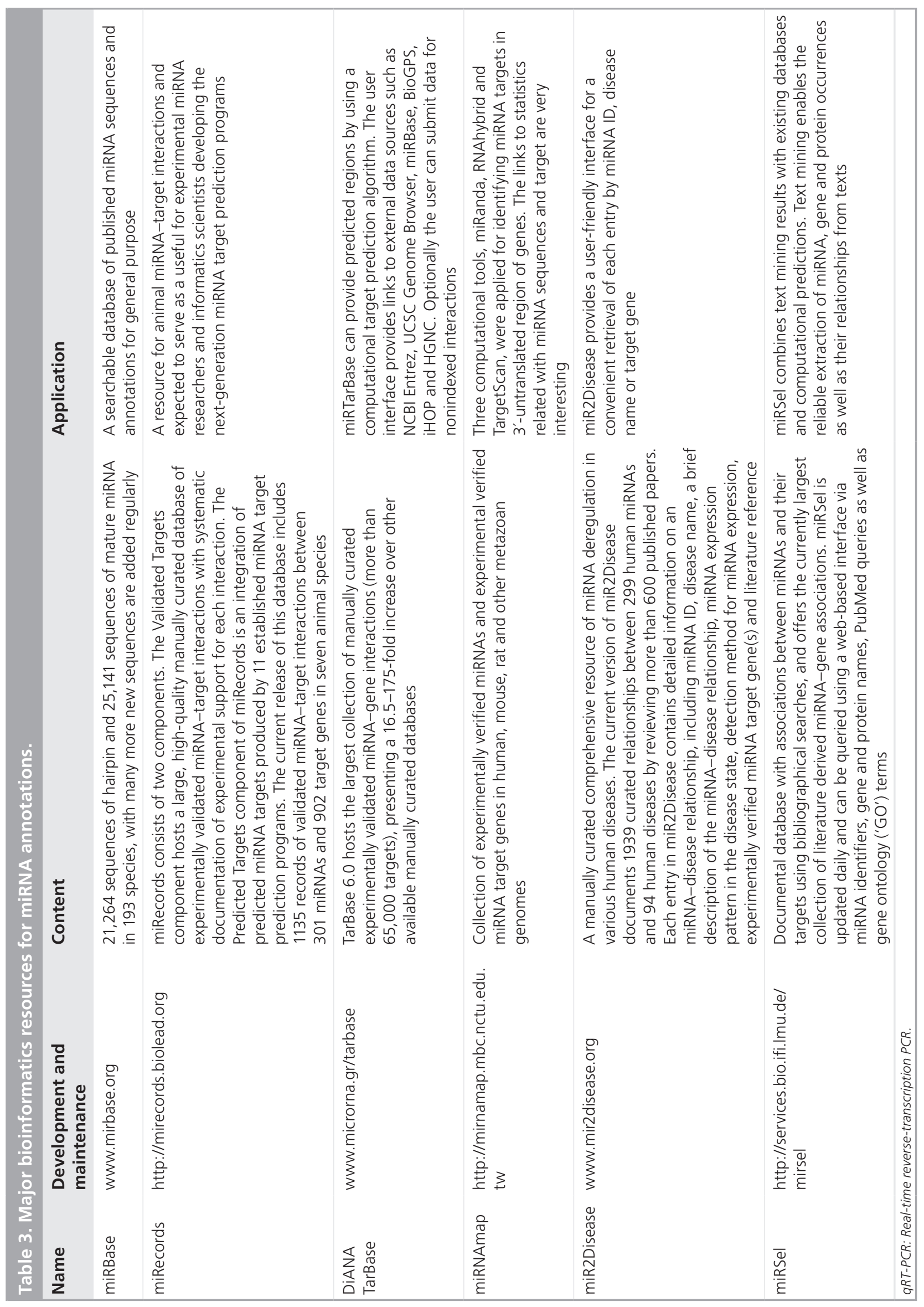




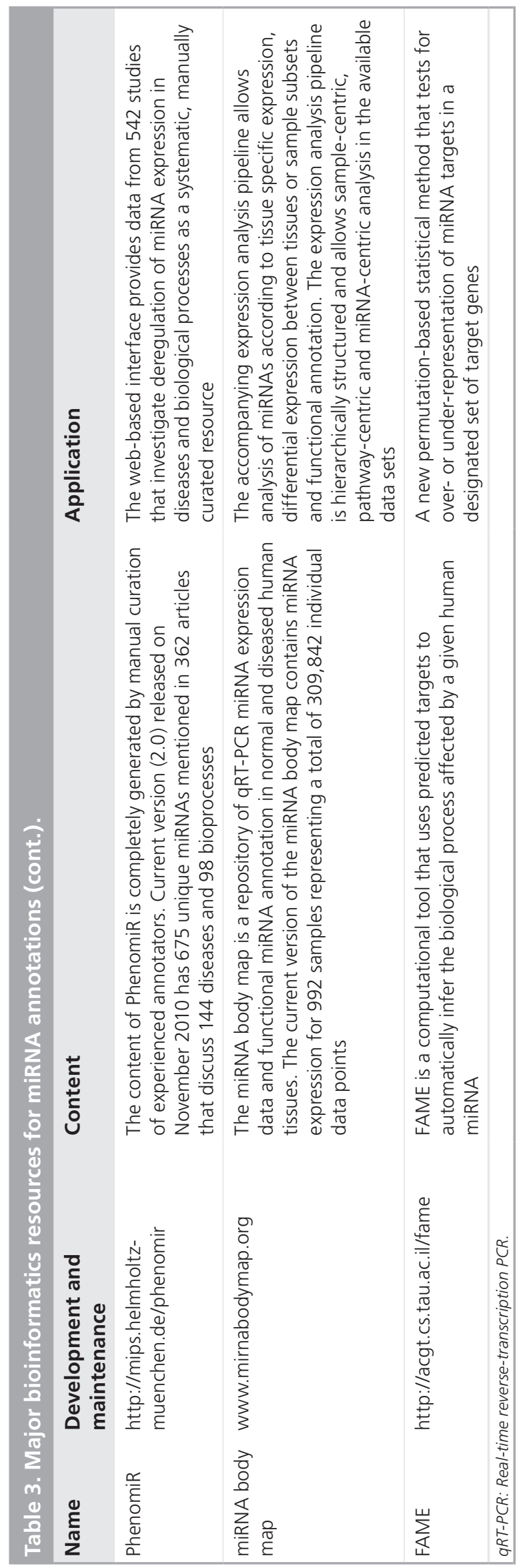

focus on prediction of the fruit fly and mammalian genomes [61-63]. With the progression of research on important roles of miRNAs in human diseases, several computational and experimental approaches toward miRNA target genes discovery have been developed and tested [64,65]. Major bioinformatic resources for miRNA research and their applications are listed in Table 3. Among these, miRBase is a comprehensive online repository of miRNA sequences and annotations. The most updated version of miRBase was released on 1 August 2012, containing 21,264 sequences of hairpin and 25,141 sequences of mature miRNA in 193 species (accessed date: 28 July 2013) and many more new sequences are added regularly [66]. In addition, as the dramatic increase of experimental data of miRNAs, more and more databases that curate and collect experimentally verified miRNA targets have emerged. For example, miRecords [67] and TarBase [68] provide computationally predicted or experimentally validated target genes for miRNAs and take into account the biological functioning of miRNAs, such as complex target gene-binding parameters.

\section{Potential as translational biomarkers of miRNAs for DILI management}

The miRNA profiling studies over the recent years have indicated the involvement of miRNAs in the pathobiology of various diseases including cancer [27,69], infectious diseases [70], diabetes, cardiovascular diseases, neurological diseases and immune system disorders [71-74]. The importance of miRNAs in liver disease is also being increasingly recognized [75,76]. Specific miRNA signatures have been identified in various etiologies of liver diseases, such as developmental disorders, fibrosis, hepatocellular carcinoma and hepatitis [77,78]. Summary of miRNAs in liver diseases are listed at Box 1. Among of them, miR-122 and 192, miR193 and miR155 have drawn great attention for their role in various liver diseases [79-81].

DILI represents a leading cause of acute liver failure, and major attrition to drug discovery and development [82,83], and has put the onus on pharmaceutical companies and regulatory agencies to protect the public health [84]. With the exception of acetaminophen, most drugs to cause DILI in humans in an unpredictable manner are cause idiosyncratic DILI [82,85]. Multiples factors have been reported to be associated with DILI occurrence, including genetic predisposition and environmental effects such as age, sex and obesity [86-88]. The difficulty in predicting DILI has prompted many studies to identify reliable and 
specific biomarkers for liver injury. A number of exploratory biomarkers are currently under investigation [89,90]. miRNAs have been attracting great attention as potential biomarkers for liver diseases due to their tissue-specific nature and stability in biofluids. In addition, the high degree of cross-species conversation of miRNA sequences facilitates potential of translatability of miRNA biomarker assays from preclinical models and humans.

TABLE 4 lists a summary of major studies reporting miRNAs as potential biomarkers for DILI. To date, most available data on miRNAs in DILI are related to acetaminophen-induced acute liver failure. Indeed, and notably, many of the studies have demonstrated that levels of miR-122, a liver-enriched miRNA accounting for approximately $70 \%$ of total hepatic miRNAs, was increased many fold in the blood of DILI over the controls [17,91]. Expression of miR-122 is liver specific and inhibition of miR-122 expression in mice leads to a downregulation of cholesterol and lipid metabolism, specifically downregulating the key enzyme phosphomevalonate kinase. Remarkably, silencing miR-122 in high-fat diet-fed mice resulted in a significant reduction of hepatic steatosis, which was associated with reduced cholesterol synthesis rates and stimulation of hepatic fatty acid oxidation [92]. miR-122 targets the mRNAs encoding PPAR $\beta / \delta$ and SMARCD1/BAF60a, which are themselves circadian regulators of metabolism [93]. Another study shows that miR-122 controls systemic iron homeostasis in mice [94]. However, the mechanisms causing a decrease in levels of miR-122 after DILI are not clear. The most probable explanation is that damaged hepatocyte releases these miRNAs into the circulation. Current evidence suggests that serum miR-122 is at least as informative as ALT in both preclinical models and humans with acetaminophen-induced liver injury. To investigate the potential utility of miRNAs as markers of human DILI, Starkey Lewis et al. found that miR-122 correlated with peaks ALT, but not prothrombin time or total bilirubin concentration in acetaminophen patients [89,95]. Nevertheless, miR-122 alone may not be an ideal DILI biomarker because it does not distinguish benign clinical ALT elevations (e.g., following administration of heparin) from serious liver injury potential. In addition, miR-192 and miR-193 are reported to be downregulated in a time- and dose-dependent manner in rats treated with acetaminophen [17,96]. Lack of understanding of the mechanisms underlying the roles of miR-122 and miR-192 in the biological process of DILI leave many uncertainties about this miRNA as a translatable biomarker that can be utilized in the clinical practice.

Controversially, miR-155 has been reported to be associated with inflammatory liver disease and fibrosis. With an emerging role in regulating immune response, this miRNA is essential for normal B-cell differentiation and antibody production, and is involved in inflammation by regulating members of the superfamilies of TNF receptors and their ligands, such as TNF and TRAMP (TNFRSF25) [97]. In parallel with those identified genomic profiles, alcoholic liver disease (ALD) also correlated with deregulated levels of specific miRNAs. Recent research performed by Bala et al. provided important insights into the role of miRNAs in ALD [98]; the upregulation of miR-155, via NF- $\kappa$ B signaling, might contribute to alcohol liver injury through

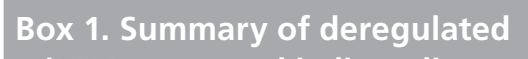
miRNAs reported in liver diseases.

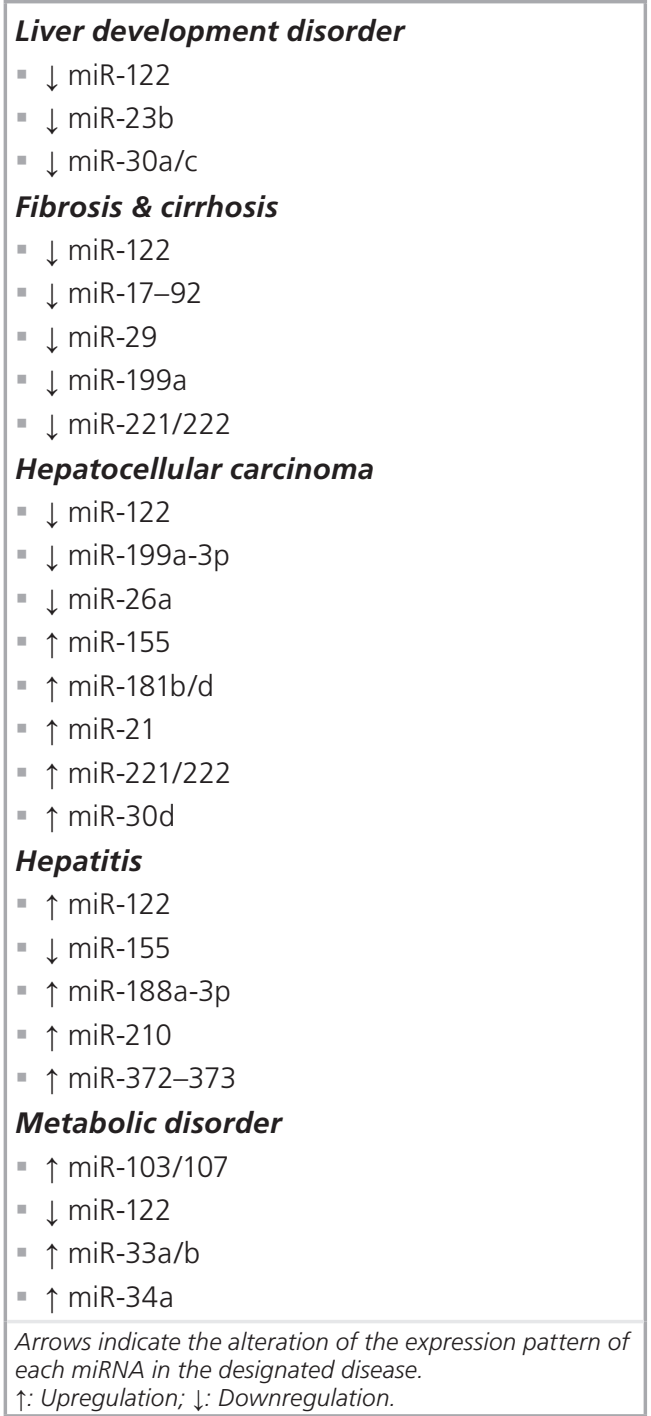




\section{Table 4. Reported studies on circulating miRNAs in drug-induced liver injury.}

\begin{tabular}{|c|c|c|c|c|c|}
\hline Liver injury & Species & Sample type & Method & miRNA expression trend & Ref. \\
\hline DILI (APAP-induced) & Mouse & Plasma & $\begin{array}{l}\text { SYBR }^{\circledR} \text { Green-based } \\
\text { qPCR }\end{array}$ & $\begin{array}{l}\operatorname{miR}-574-5 p \uparrow, \operatorname{miR}-135 a^{*} \uparrow, \operatorname{miR}-466 \mathrm{~g} \uparrow, \\
\text { miR-1196 } \uparrow, \text { miR-466f-3p } \uparrow, \text { miR-877 } \uparrow, \\
\text { miR-342-3p } \downarrow, \text { miR-195 } \downarrow \text {, miR-375 } \downarrow \\
\text { miR-29c } \downarrow, \text { miR-148a, miR-652 } \downarrow\end{array}$ & [9] \\
\hline APAP and $\mathrm{CCl} 4$ & Rat & Serum and urine & $\begin{array}{l}\text { SYBR Green-based } \\
\text { qPCR }\end{array}$ & $\begin{array}{l}44 \text { serum miRNAs and } 28 \text { urinary } \\
\text { miRNAs } \uparrow\end{array}$ & [36] \\
\hline $\begin{array}{l}\text { ALD, DILI, induced } \\
\text { inflammation }\end{array}$ & Mouse & Serum or plasma & $\operatorname{TaqMan}^{\circledR} \mathrm{qPCR}$ & $\operatorname{miR}-122 \uparrow, \operatorname{miR}-155 \uparrow, \operatorname{miR}-146 a \uparrow$ & [104] \\
\hline Herb and APAP-DILI & Rat & Serum & $\begin{array}{l}\text { TaqMan Rodent } \\
\text { MicroRNA Low Density } \\
\text { Arrays }\end{array}$ & $\operatorname{miR}-122 \uparrow, \operatorname{miR}-192 \uparrow, \operatorname{miR}-193 \uparrow$ & {$[8]$} \\
\hline APAP-DILI & Human & Serum & TaqMan qPCR & miR-122 $\uparrow$, miR-192 $\uparrow$ & [95] \\
\hline $\begin{array}{l}\text { Chronic hepatitis B, } \\
\text { muscle disorder (human): } \\
\text { DILI, ALD (mouse) }\end{array}$ & Human/mouse & Plasma & $\begin{array}{l}\text { SYBR green-based } \\
\text { qPCR }\end{array}$ & $\operatorname{miR}-122 \uparrow, \operatorname{miR}-192 \uparrow$ & {$[105]$} \\
\hline $\begin{array}{l}\text { Hepatotoxic-induced } \\
\text { injury }\end{array}$ & Rat & Plasma & TaqMan qPCR & $\operatorname{miR}-122 \uparrow$ & [106] \\
\hline DILI & Mouse & Plasma & Mouse miRNA arrays & 25 miRNAs $\uparrow, 19$ miRNAs $\downarrow$ & [17] \\
\hline
\end{tabular}

activation of specific macrophages (Kupffer cells) by increasing TNF- $\alpha$.

\section{Opportunities \& challenges in discovery miRNA as translational biomarkers for DILI in humans}

The role of miRNAs as translational biomarkers for DILI is promising, particularly with regards to circulating miRNAs, which potentially offer a less invasive method of diagnosing liver injury. They have progressed from discovery to biomarker and remain at the forefront of research into disease pathogenesis and drug development programs. Despite significant advances in recent years, the miRNA mimic and antagonist technologies have not yet been validated as platforms for the development of safe and effective human therapeutics. In addition, prior to clinical application, there are major challenges such as the need for careful validation of diagnostic miRNA candidates in well-annotated clinical studies, as well as technical issues such as quantitation, standardization and normalization of expression. As a translatable biomarker, detection and quantification should be robust, rapid, simple, accurate, reproducible and inexpensive. miRNA detection currently falls short of all of these prerequisites. It is unlikely that any single miRNA will achieve the desired level of diagnostic or prognostic accuracy, as evidence is increasing that increased levels of particular miRNAs can be associated with several different types of diseases or functional changes.
The lack of association between miRNAs and insightful mechanistic information on DILI is another hurdle in the translation of miRNAs as biomarkers into the clinical setting. More work needs to be carried out to understand the complex biological function of miRNAs, their roles in pathogenesis and the safety of compounds that alter their levels. The extent and mechanism of function of extracellular miRNAs are largely unknown. It is believed that efforts to assess the utility of miRNAs for DILI as translational biomarkers can be better achieved by conducting a comprehensive investigation on the alterations of miRNAs in liver tissues treated by a large number of drugs that represent a broad range of DILI types and therapeutic uses. Such an exercise could provide more convincing evidence to elucidate the possible mechanisms underlying the phenotypes of DILI, and, potentially, translate the utilization of miRNAs biomarkers into clinical use. Active and vigorous investigations are ongoing in several laboratories across academia and industry to decipher the precise molecular functions and mechanisms of action for key miRNAs with potential for drug toxicity prediction. Such studies should lead to the development of reliable and cost-effective miRNAbased biomarker platforms for routine use in the DILI clinic in the next few years. Knowledge gained from these efforts will surely pave the way for designing safe drugs and will revolutionize the way we diagnose and predict toxicity including DILI. 


\section{Future perspective}

In conclusion, there is considerable excitement surrounding the application of miRNAs in the biomarker field, which is well promised, given their stability and relative ease of detection. To bring these miRNAs into clinical use, crossspecies validation, screening of additional hepatotoxicants and mechanistic-based information of corresponding miRNAs to DILI need to be investigated in future. We hope the advances in the analyses of circulating miRNAs reviewed here will lead to more efforts toward using miRNA as biomarkers of DILI, as well as other pathologies, and will facilitate the development of screening, prediction and monitoring tests for these diseases.

\section{Disclaimer}

The views presented in this article do not necessarily reflect current or future opinion or policy of the US FDA.
Any mention of commercial products is for clarification

and not intended as endorsement.

\section{Financial \& competing interests disclosure}

The authors have no relevant affliations or financial involvement with any organization or entity with a financial interest in or financial conflict with the subject matter or materials discussed in the manuscript. This includes employment, consultancies, honoraria, stock ownership or options, expert testimony, grants or patents received or pending, or royalties.

No writing assistance was utilized in the production of this manuscript.

\section{Open Access}

This work is licensed under the Creative Commons Attribution-NonCommercial 3.0 Unported License. To view a copy of this license, visit http://creativecommons. org/licenses/by-nc-nd/3.0/

\section{Executive summary}

\section{Technical challenges in preanalytical processing of RNA samples}

- miRNAs are a family of regulatory RNAs with a large role in multiple biology processes and functions.

- Lack of standardized protocols for miRNA isolation and quality assessment is a significant challenge for preanalytical processing for miRNA research.

\section{Bioinformatics technologies for miRNA measurements \& targets prediction}

- Several computational and experimental approaches toward miRNA target gene discovery have been developed and are available for the research community.

- Identification of miRNA targets to understand how they fine tune so many biological processes in both healthy and diseased tissue needs deeper mechanistic study of miRNAs.

Potential of miRNAs as translational biomarkers for drug-induced liver injury management in humans

- miRNAs in liver disease: specific miRNA signatures have been identified in various etiologies of liver diseases.

- miRNAs in drug-induced liver injury (DILI): DILI can mimic most types of liver disease and share similar mechanisms. Thus, liver disease-specific miRNAs may be applicable for DILI.

\section{Perspectives \& challenges in discovering \& translating miRNA biomarkers of DILI in clinical applications}

- Promise: with regards to circulating miRNAs and liver specificity, miRNAs offer a great potential as novel biomarkers for DILI.

- Challenges: there is still need for more additional hepatotoxicants and mechanistic-based information on miRNAs in DILI as well as cross-species validation to facilitate the translation of miRNA biomarkers from preclinical setting to clinical application.

\section{References}

Papers of special note have been highlighted as: - of interest

"w of considerable interest

1 Bjornsson E, Bergmann O, Bjornsson HK et al. The frequency of drug-induced liver injury (DILI) among patients receiving potentially hepatotoxic drugs: a population based study. Hepatology 56(S1), 594A-595A (2012) (Abstract 823).

2 Grant LM, DC Rockey. Drug-induced liver injury. Curr. Opin. Gastroenterol. 28(3), 198-202 (2012).

3 Lee WM. Acetaminophen and the US Acute Liver Failure Study Group: lowering the risks of hepatic failure. Hepatology 40(1), 6-9 (2004).

4 Filipowicz W, SN Bhattacharyya, Sonenberg N. Mechanisms of post-transcriptional regulation by microRNAs: are the answers in sight? Nat. Rev. Genet. 9(2), 102-114 (2008).

5 Koturbash I, Beland FA, Pogribny IP. Role of microRNAs in the regulation of drug metabolizing and transporting genes and the response to environmental toxicants. Expert Opin. Drug Metab. Toxicol. 8(5), 597-606 (2012).

6 Lu J, Getz G, Miska EA et al. MicroRNA expression profiles classify human cancers. Nature 435(7043), 834-838 (2005).
7 Hansen TB, Jensen TI, Clausen BH et al. Natural RNA circles function as efficient microRNA sponges. Nature 495(7441), 384-388 (2013).

8 Su YW, Chen X, Jiang ZZ et al. A panel of serum microRNAs as specific biomarkers for diagnosis of compound- and herb-induced liver injury in rats. PLoS ONE7(5), e37395 (2012).

9 Ward J, Bala S, Petrasek J, Szabo G. Plasma microRNA profiles distinguish lethal injury in acetaminophen toxicity: a research study. World J. Gastroenterol. 18(22), 2798-2804 (2012).

10 Blondal T, Jensby Nielsen S, Baker A et al. Assessing sample and miRNA profile quality 
in serum and plasma or other biofluids. Methods 59(1), S1-S6 (2012).

11 Gallego JA, Gordon ML, Claycomb K, Bhatt $\mathrm{M}$, Lencz T, Malhotra AK. In vivo microRNA detection and quantitation in cerebrospinal fluid. J. Mol. Neurosci. 47(2), 243-248 (2012).

12 Alevizos I,Illei GG. MicroRNAs as biomarkers in rheumatic diseases. Nat. Rev. Rheumatol. 6(7), 391-398 (2010).

13 Frampton AE, Gall TM, Castellano L, Stebbing J, Jiao LR, Krell J. Towards a clinical use of miRNAs in pancreatic cancer biopsies. Expert Rev. Mol. Diagn. 13(1), 31-34 (2013).

14 Weber JA, Baxter DH, Zhang $S$ et al. The microRNA spectrum in 12 body fluids. Clin. Chem. 56(11), 1733-1741 (2010).

15 Armistead D, Estep JM, Elariny $\mathrm{H}$ et al. Systems biology analysis of non-alcoholic steatohepatitis related miRNA expression. Hepatology 56(S1), 266A (2012) (Abstract 147).

16 Hand NJ, Kennedy M, Le Guen CL et al. Cholestasis induces a conserved, adaptive, liver miRNA response. Hepatology 56(S1), 197A (2012) (Abstract 14).

17 Wang K, Zhang S, Marzolf B et al. Circulating microRNAs, potential biomarkers for drug-induced liver injury. Proc. Natl Acad. Sci. USA 106(11), 4402-4407 (2009).

-1I Demonstrated that both miR-122 and miR-192, specifically enriched in mice liver, are highly expressed in plasma and are expressed in a dose- and time-dependent manner upon treatment of acetaminophen.

18 Carthew RW, Sontheimer EJ. Origins and mechanisms of miRNAs and siRNAs. Cell 136(4), 642-655 (2009).

19 Winter J, Jung S, Keller S, Gregory RI, Diederichs S. Many roads to maturity: microRNA biogenesis pathways and their regulation. Nat. Cell Biol. 11(3), 228-234 (2009).

20 Du T, ZamorePD. microPrimer: the biogenesis and function of microRNA. Development 132(21), 4645-4652 (2005).

21 Feero WG, Guttmacher AE, CollinsFS. genomic medicine: genomic medicine - an updated primer. N. Eng. J. Med. 362(21), 2001-2011 (2010).

22 Zhou Q, Haupt S, Prots I et al. miRNA regulation of cell proliferation by targeting the expression of GARP. Immunology 137(S1), 74 (2012) (Abstract W30.002).

23 He JF, Luo YM, Wan XH, Jiang D. Biogenesis of miRNA-195 and its role in biogenesis, the cell cycle, and apoptosis. J. Biochem. Mol. Toxicol. 25(6), 404-408 (2011).
24 Ferraz C, Lorenz S, Wojtas B, Bornstein SR, Paschke R, Eszlinger M. Inverse correlation of miRNA and cell cycle-associated genes suggests influence of miRNA on benign thyroid nodule tumorigenesis. Exp. Clin. Endocrinol. Diabetes 121(3), OP5_38 (2013).

$25 \mathrm{Xu} X$, Fan Z, Kang L et al. Hepatitis B virus X protein represses miRNA-148a to enhance tumorigenesis. J. Clin. Invest. 123(2), 630-645 (2013).

26 Bauersachs J, Thum T. Biogenesis and regulation of cardiovascular microRNAs. Circ. Res. 109(3), 334-347 (2011).

27 Kong YW, Ferland-McCollough D, Jackson $\mathrm{TJ}$, Bushell M. microRNAs in cancer management. Lancet Oncol. 13(6), e249-e258 (2012).

28 Lorenzen JM, Haller H, Thum T. MicroRNAs as mediators and therapeutic targets in chronic kidney disease. Nat. Rev. Nephrol. 7(5), 286-294 (2011).

29 Mendell JT, Olson EN. MicroRNAs in stress signaling and human disease. Cell 148(6), 1172-1187 (2012).

30 Kim VN. MicroRNA biogenesis: coordinated cropping and dicing. Nat. Rev. Mol. Cell Biol. 6(5), 376-385 (2005).

31 Barabási AL, Gulbahce N, Loscalzo J. Network medicine: a network-based approach to human disease. Nat. Rev. Genet. 12(1), 56-68 (2011).

32 Grskovic M, Javaherian A, Strulovici B, Daley GQ. Induced pluripotent stem cells - opportunities for disease modelling and drug discovery. Nat. Rev. Drug Discov. 10(12), 915-929 (2011).

33 Cortez MA, Bueso-Ramos C, Ferdin J, LopezBerestein G, Sood AK, Calin GA. MicroRNAs in body fluids-the mix of hormones and biomarkers. Nat. Rev. Clin. Oncol. 8(8), 467-477 (2011).

34 Jabed A, Wagner S, McCracken J, Wells DN, Laible G. Targeted microRNA expression in dairy cattle directs production of betalactoglobulin-free, high-casein milk. Proc. Natl Acad. Sci. USA 109(42), 16811-16816 (2012).

35 Ogawa Y, Taketomi Y, Murakami M, Tsujimoto M, Yanoshita R. Small RNA transcriptomes of two types of exosomes in human whole saliva determined by next generation sequencing. Biol. Pharm. Bull. 36(1), 66-75 (2013).

36 Yang X, Greenhaw J, Shi Q et al. Identification of urinary microRNA profiles in rats that may diagnose hepatotoxicity. Toxicol. Sci. 125(2), 335-344 (2012).

37 Blondal T, Jensby Nielsen S, Baker A et al. Assessing sample and miRNA profile quality in serum and plasma or other biofluids. Methods 59(1), S1-S6 (2013).
38 Li Y, Kowdley KV. Method for microRNA isolation from clinical serum samples. Anal. Biochem. 431(1), 69-75 (2012).

39 Rajput SK, Dave VP, Rajput A, Pandey HP, Datta TK, Singh RK. A column-based rapid method for the simultaneous isolation of DNA, RNA, miRNA and proteins. Cell. Biol. Int. 36(9), 779-783 (2012).

40 Sharkey JW, Antoine DJ, Park BK. Validation of methods involving miRNA isolation, purification and quantification and the potential of miRNAs to be used as biomarkers of nephrotoxicity. Toxicology 290(2-3), 136-137 (2011).

41 Sourvinou IS, Markou A, Lianidou ES. Quantification of circulating miRNAs in plasma: effect of preanalytical and analytical parameters on their isolation and stability. J. Mol. Diagn. 15(6), 827-834 (2013).

42 Sharkey JW, Antoine DJ, Park BK. Validation of the isolation and quantification of kidney enriched miRNAs for use as biomarkers. Biomarkers 17(3), 231-239 (2012).

43 Turchinovich A, Weiz L, Langheinz A, Burwinkel B. Characterization of extracellular circulating microRNA. Nucleic Acids Res. 39(16), 7223-7233 (2011).

44 Lee Y, El Andaloussi S, Wood MJ. Exosomes and microvesicles: extracellular vesicles for genetic information transfer and gene therapy. Hum. Mol. Genet. 21, R125-R134 (2012).

45 Arroyo JD, Chevillet JR, Kroh EM et al. Argonaute 2 complexes carry a population of circulating microRNAs independent of vesicles in human plasma. Proc. Natl Acad. Sci. USA 108(12), 5003-5008 (2011).

46 Arroyo JD, Chevillet JR, Kroh EM et al. Argonaute 2 complexes carry a population of circulating microRNAs independent of vesicles in human plasma. Proc. Natl. Acad. Sci. USA 108(12), 5003-5008 (2011).

47 Wang B, Howel P, Bruheim S et al. Systematic evaluation of three microRNA profiling platforms: microarray, beads array, and quantitative real-time PCR array. PLoS ONE 6(2), e17167 (2011)

48 Kim H, Choi J, Cho M, Park H. A PNA microarray platform for miRNA expression profiling using on-chip labeling technology. Biochip J. 6(1), 25-33 (2012).

49 Wang ST, Li C, Liu L. miRNA microarray technology in miRNA profiling. Curr. Bioinform. 4(2), 141-148 (2009).

50 Hawkins RD, Hon GC, Ren B. Nextgeneration genomics: an integrative approach. Nat. Rev. Genet. 11(7), 476-486 (2010).

51 Meyerson M, Gabriel S, Getz G. Advances in understanding cancer genomes through second-generation sequencing. Nat. Rev. Genet. 11(10), 685-696 (2010). 
52 König J, Zarnack K, Luscombe NM, Ule J. Protein-RNA interactions: new genomic technologies and perspectives. Nat. Rev. Genet. 13(2), 77-83 (2012).

53 Gerlach D, Kriventseva EV, Rahman N, Vejnar CE, Zdobnov EM. miROrtho: computational survey of microRNA genes. Nucleic Acids Res. 37, D111-D117 (2009).

54 Thakur V, Wanchana S, Xu M et al. Characterization of statistical features for plant microRNA prediction. BMC Genomics 12, 108 (2011)

55 Lawless N, Foroushani AB, McCabe MS, O'Farrelly C, Lynn DJ. Next generation sequencing reveals the expression of a unique miRNA profile in response to a Gram-positive bacterial infection. PLoS ONE 8(3), e57543 (2013).

56 Nekrutenko A, Taylor J. Next-generation sequencing data interpretation: enhancing reproducibility and accessibility. Nat. Rev. Genet. 13(9), 667-672 (2012).

57 Wang B, Xi Y. Challenges for microRNA microarray data analysis. Microarrays 2(2), 34-50 (2013).

58 Akbari Moqadam F, Pieters R, den Boer ML. The hunting of targets: challenge in miRNA research. Leukemia 27(1), 16-23 (2012).

59 Yan X, Liang H, Deng T et al. The identification of novel targets of miR-16 and characterization of their biological functions in cancer cells. Mol. Cancer 12(1), 1-11 (2013).

60 Sethupathy P, Megraw M, Hatzigeorgiou AG. A guide through present computational approaches for the identification of mammalian microRNA targets. Nat. Methods 3(11), 881-886 (2006).

61 Lewis BP, Shih IH, Jones-Rhoades MW, Bartel DP, Burge CB. Prediction of mammalian microRNA targets. Cell 115(7), 787-798 (2003).

62 Krek A, Grün D, Poy MN et al. Combinatorial microRNA target predictions. Nat. Genet. 37(5), 495-500 (2005).

63 Enright AJ, John B, Gaul U, Tuschl T, Sander C, Marks DS. MicroRNA targets in Drosophila. Genome Biol. 5(1), R12R1 (2004).

64 Jiang Q, Wang Y, Hao Y et al. miR2Disease: a manually curated database for microRNA deregulation in human disease. Nucleic Acids Res. 37(Suppl. 1), D98-D104 (2009).

65 Hindorff LA, Sethupathy P, Junkins HA et al. Potential etiologic and functional implications of genome-wide association loci for human diseases and traits. Proc. Natl. Acad. Sci. USA 106(23), 9362-9367 (2009).

66 K Kozomara A, Griffiths-Jones S. miRBase: integrating microRNA annotation and deepsequencing data. Nucleic Acids Res. 39, D152-D157 (2011).
67 Xiao F, Zuo Z, Cai G, Kang S, Gao X, Li T. et al. miRecords: an integrated resource for microRNA-target interactions. Nucleic Acids Res. 37, D105-D110 (2009).

68 Vergoulis T, Vlachos IS, Alexiou P et al. TarBase 6.0: capturing the exponential growth of miRNA targets with experimental support. Nucleic Acids Res. 40(D1), D222-D229 (2012).

69 Luo D, Wilson JM, Harvel N et al. A systematic evaluation of miRNA:mRNA interactions involved in the migration and invasion of breast cancer cells. J. Transl. Med. 11, 57 (2013).

70 Motta V, Angelici L, Nordio F et al. Integrative analysis of miRNA and inflammatory gene expression after acute particulate matter exposure. Toxicol. Sci. 132(2), 307-316 (2013)

71 Wakili R, Clauß S, Kääb S. Molecular mechanisms of atrial fibrillation. Potential role of microRNAs as new therapeutic targets and potential biomarkers. Herz 37(2), 166-171 (2012).

72 Samantarrai D, Dash S, Chhetri B, Mallick B. Genomic and epigenomic cross-talks in the regulatory landscape of miRNAs in breast cancer. Mol. Cancer Res. 11(4), 315-328 (2013).

73 Steinfeld I, Navon R, Ach R, Yakhini Z. miRNA target enrichment analysis reveals directly active miRNAs in health and disease. Nucleic Acids Res. 41(3), e 45 (2013).

74 Van Roosbroeck K, Pollet J, Calin GA. miRNAs and long noncoding RNAs as biomarkers in human diseases. Expert Rev. Mol. Diagn. 13(2), 183-204 (2013).

75 Takahashi K, Yan I, Wen HJ, Patel T. microRNAs in liver disease: from diagnostics to therapeutics. Clin. Biochem. 46(10-11), 946-952 (2013).

76 Ji J, Shi J, Budhu A et al. MicroRNA expression, survival, and response to interferon in liver cancer. N. Eng. J. Med. 361(15), 1437-1447 (2009).

77 Szabo G, Bala S. MicroRNAs in liver disease. Nat. Rev. Gastroenterol. Hepatol. 10, 542-552 (2013).

78 Cermelli S, Ruggieri A, Marrero JA, Ioannou GN, Beretta L. Circulating microRNAs in patients with chronic hepatitis $\mathrm{C}$ and nonalcoholic fatty liver disease. PLoS ONE 6(8), e23937 (2011).

79 Nunnari G, Schnell MJ. MicroRNA-122: a therapeutic target for hepatitis $\mathrm{C}$ virus (HCV) infection. Front. Biosci. (Schol. Ed.) 3, 1032-1037 (2011).

80 Szabo G, Bala S. MicroRNAs in liver disease. Nat. Rev. Gastroenterol. Hepatol. 10(9), 542-552 (2013)
81 Wang XW, Heegaard NH, Orum H. MicroRNAs in liver disease. Gastroenterology 142(7), 1431-1443 (2012).

82 Tarantino G, Di Minno MN, Capone D. Drug-induced liver injury: is it somehow foreseeable? World J. Gastroenterol. 15(23), 2817 (2009).

83 Reuben A, Koch DG, Lee WM; Acute Liver Failure Study Group. Drug-induced acute liver failure: results of a U.S. multicenter, prospective study. Hepatology 52(6), 2065-2076 (2010).

84 Tarantino G, Conca P, Basile V et al. A prospective study of acute drug-induced liver injury in patients suffering from non-alcoholic fatty liver disease. Hepatol. Res. 37(6), 410-415 (2007).

85 Kaplowitz N. Avoiding idiosyncratic DILI: two is better than one. Hepatology 58(1), 15-17 (2013)

86 Chalasani N, Björnsson E. Risk factors for idiosyncratic drug-induced liver injury. Gastroenterology 138(7), 2246-2259 (2010).

87 Daly AK, Donaldson PT, Bhatnagar P et al. $H L A-B^{*} 5701$ genotype is a major determinant of drug-induced liver injury due to flucloxacillin. Nat. Genet. 41(7), 816-819 (2009)

88 Tarantino G, Pezzullo MG, di Minno MN et al. Drug-induced liver injury due to "natural products" used for weight loss: a case report. World J. Gastroenterol. 15(19), 2414-2417 (2009).

89 Starkey Lewis PJ, Merz M, Couttet P et al. Serum microRNA biomarkers for druginduced liver injury. Clin. Pharmacol. Ther 92(3), 291-293 (2012).

- Discussed how cellular miRNAs are released into the extracellular environment, the utility of circulating miRNAs as potential biomarkers of acute drug-induced liver injury in humans and correlations with existing biomarkers of drug-induced liver injury in acetaminophen toxicity.

90 Amacher DE, Schomaker SJ, Aubrecht J. Development of blood biomarkers for druginduced liver injury: an evaluation of their potential for risk assessment and diagnostics. Mol. Diagn. Ther. 17(6), 343-354 (2013).

91 Bala S, Petrasek J, Mundkur $S$ et al. Circulating microRNAs in exosomes indicate hepatocyte injury and inflammation in alcoholic, druginduced, and inflammatory liver diseases. Hepatology 56(5), 1946-1957 (2012).

92 Esau C, Davis S, Murray SF et al. miR-122 regulation of lipid metabolism revealed by in vivo antisense targeting. Cell Metab. 3(2), 87-98 (2006).

93 Gatfield D, Le Martelot G, Vejnar CE et al. Integration of microRNA miR-122 in hepatic 
circadian gene expression. Genes Dev. 23(11), 1313-1326 (2009).

94 Castoldi M, Vujic Spasic M, Altamura S et al. The liver-specific microRNA miR-122 controls systemic iron homeostasis in mice. J. Clin. Invest. 121(4), 1386-1396 (2011).

95 Starkey Lewis PJ, Dear J, Platt V et al. Circulating microRNAs as potential markers of human drug-induced liver injury. Hepatology 54(5), 1767-1776 (2011).

96 Su YW, Chen X, Jiang ZZ et al. A panel of serum microRNAs as specific biomarkers for diagnosis of compound-and herb-induced liver injury in rats. PLoS ONE7(5), e37395 (2012).

97 Gracias DT, Stelekati E, Hope JL et al. The microRNA miR-155 controls CD8 ${ }^{+} \mathrm{T}$ cell responses by regulating interferon signaling. Nat. Immunol. 14(6), 593-602 (2013).

98 Bala S, Szabo G. MicroRNA signature in alcoholic liver disease. Int. J. Hematol. 2012, 1-6 (2012)
99 Eldh M, Lötvall J, Malmhäll C, Ekström K. Importance of RNA isolation methods for analysis of exosomal RNA: evaluation of different methods. Mol. Immunol. 50(4), 278-286 (2012).

100 Dijkstra JR, Mekenkamp LJ, Teerenstra S, De Krijger I, Nagtegaal ID. MicroRNA expression in formalin-fixed paraffin embedded tissue using real time quantitative PCR: the strengths and pitfalls. J. Cell. Mol. Med. 16(4), 683-690 (2012).

101 Kolbert CP, Feddersen RM, Rakhshan F et al. Multi-platform analysis of microRNA expression measurements in RNA from fresh frozen and FFPE tissues. PLoS ONE 8(1), e52517 (2013).

102 Wang K, Yuan Y, Cho JH, McClarty S, Baxter D, Galas DJ. Comparing the MicroRNA spectrum between serum and plasma. PLoS ONE 7(7), e41561 (2012).
103 Alvarez ML, Khosroheidari M, Kanchi Ravi R, DiStefano JK. Comparison of protein, microRNA, and mRNA yields using different methods of urinary exosome isolation for the discovery of kidney disease biomarkers. Kidney Int. 82(9), 1024-1032 (2012).

104 Bala S, Petrasek J, Mundkur S et al. Circulating microRNAs in exosomes indicate hepatocyte injury and inflammation in alcoholic, drug-induced, and inflammatory liver diseases. Hepatology 56(5), 1946-1957 (2012).

105 Zhang Y, Jia Y, Zheng R et al. Plasma microRNA-122 as a biomarker for viral-, alcohol-, and chemical-related hepatic diseases. Clin. Chem. 56(12), 1830-1838 (2010).

106 Laterza OF, Lim L, Garrett-Engele PW et al. Plasma microRNAs as sensitive and specific biomarkers of tissue injury. Clin. Chem. 55(11), 1977-1983 (2009). 